\title{
Finite element analysis of flexural behavior of different fiber reinforced ultra-high-strength concrete beam under different environments
}

\author{
YUQUAN ${ }^{1}$, ChangchunPEI ${ }^{1, a,{ }^{*}}$ \\ ${ }^{1}$ Department of Structural Engineering,College of Engineering, YanbianUniversity, Yanji, 133002, \\ China \\ ${ }^{a, \star}$ Corresponding author:peicc@yub.edu.cn
}

Keywords: ultra high strength concrete beam; cracking load; ultimate load;deflection;nonlinear finite element;

\begin{abstract}
In this paper,finite element simulation of ANSYS was carried out to study initial crack load,ultimate load and load-deflection relationship of ultra-high-strength concrete beam with different ratio of steel fiber and PVA fiberunder general environment and corrosive environment respectively.The results show that with the increase of the content of steel fiber,the initial crack load and ultimate load of ultra-high-strength concrete beam are increasing;and with the increase of fiber content,the toughness of the beam is improved;with the increase of the content of PVA fiber,the initial crack load and ultimate load of ultra-high-strength concrete beam increase first and then decrease.The incorporation of the two kind of fibers increases the toughness of the beam to a certain extent and limits the occurrence and development of the crack. When steel fiber mixing rate was 3\% in common environment,initial crack load and ultimate load is increased by $155.4 \%$ and $7.0 \%$ compared with HSC beam,respectively. When PVA fiber mixing rate was $0.5 \%$ in the case of easy corrosion,initial crack load and ultimate load is increased by $56.6 \%$ and $3.7 \%$ compared with HSC beam,respectively, which can effectively improve the flexural performance of the ultra high strength concrete beams.
\end{abstract}

\section{Introduction}

In recent years, with the development of the construction industry, the concrete has been developed to ultra high strength and ultra high performance. The ultra high strength concrete of C100 or above has been used in the important project. However,the research data of Sun Chenghui[1], Xincheng Pu[2], Tian Yudong [3]and Ouyang Dong [4] show that, with the strength grade of concrete increases, the material brittleness increases, ultra high strength concrete can appear even burst damage phenomenon when compression. In recent years, research data show that the addition of steel fiber, PVA fiber with highstrength and high elastic modulus fiber can effectively improve the brittleness of concrete[5,6,7,8] 。 However,most researches on ultra-high-strength concrete at home and abroad are confined to material test and research, the experimental research on the fiber reinforcedultra-high-strength concrete applied to the component is less.Therefore, this article mixed with steel fiber and Polyvinyl alcohol fiber (PVA fiber) in the general environment and corrosion environment respectively. The initial cracking load and ultimate load of the ultra -high-strength concrete beams with different ratios of fiberwere analyzed by finite element analysis(FEA), which can provide reference for the engineering application of fiber reinforced ultra- high -strength concrete.

\section{Test scheme design}

In this paper, the ultra-high-strength beams with water-cement ratio of 0.22 , respectively, to change the steel fiber mixed rate of $0 \%, 1 \%, 2 \%, 3 \%$, four levels, change the PVA fiber mixing rate of $0 \%, 0.5 \%, 1.0 \%, 1.5 \%$, four levels, a total plan design 7 rectangular section beams. The length of the beam is $1500 \mathrm{~mm}$, the net span is $1200 \mathrm{~mm}$, the cross-section size is $150 \mathrm{~mm} \times 250 \mathrm{~mm}$ (see Figure 1). The longitudinal tensile reinforcement in the beam adopts 2C25 (HRB400 grade) reinforcement, the reinforcement ratio is 2.62\%, Stand reinforced with 2B8 (HRB335 grade) 
reinforcement, B8@100 (HRB335 grade) steel bars are used for the stirrups, the elastic modulus of steel bars in the beam is 200GPa. The finite element analysis of 7 ultra-high-strength concrete beams is carried out to analyze the initial crack load, the ultimate load and the load-deflection curve of the beam.

In the ANSYS modeling process, in order to simulate the two points loading of the distribution beam, the beam is loaded at the three equal points of the beam net span, And the concentrated load acting on the third point is replaced by the uniform load, The load area is $100 \mathrm{~mm} \times 150 \mathrm{~mm}$, A surface constraint of $100 \mathrm{~mm} \times 150 \mathrm{~mm}$ is applied at the distance of $150 \mathrm{~mm}$ from the edge of the beam to simulate the support form of the rigid plate, So that the simulated beam is closer to the actual force situation.
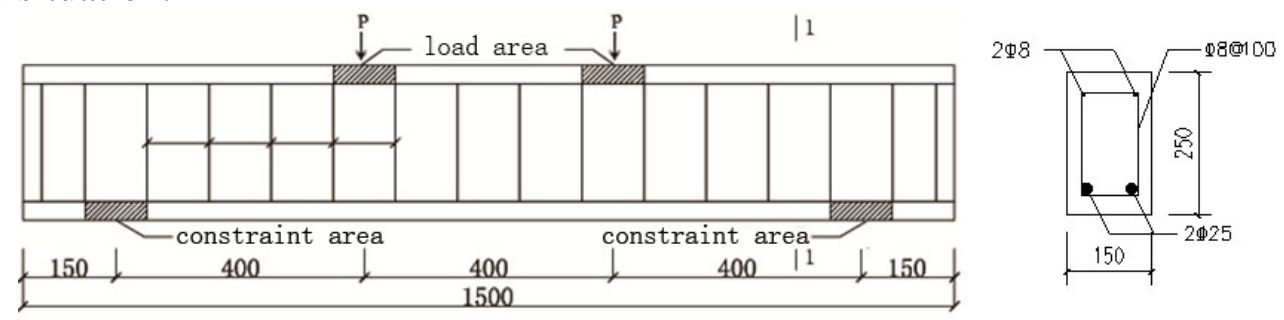

Fig.1 The structure diagram of the specimen (unit: $\mathrm{mm}$ )

Tab.1 The parameters of the test beam

\begin{tabular}{ccccrrr}
\hline Test number & $\begin{array}{c}\text { Water-cement } \\
\text { ratio }\end{array}$ & $\begin{array}{c}\text { Steel fiber } \\
\text { content } / \mathrm{kg} \cdot \mathrm{m}^{-3}\end{array}$ & $\begin{array}{c}\text { PVA fiber } \\
\text { content } / \mathrm{kg} \cdot \mathrm{m}^{-3}\end{array}$ & $\mathrm{f}_{\mathrm{c}} / \mathrm{Mpa}$ & $\mathrm{f}_{\mathrm{s}} / \mathrm{Mpa}$ & $\mathrm{E} / 10^{4} \mathrm{~N} \cdot \mathrm{mm}^{2}$ \\
\hline HSC & 0.22 & 0 & 0 & 97.2 & 6.7 & 4.970 \\
HSC-A1 & 0.22 & 78 & 0 & 105.4 & 11.4 & 5.060 \\
HSC-A2 & 0.22 & 156 & 0 & 109.4 & 15.8 & 5.120 \\
HSC-A3 & 0.22 & 234 & 0 & 112.0 & 16.1 & 5.320 \\
HSC-B1 & 0.22 & 0 & 6.5 & 94.1 & 7.7 & 5.065 \\
HSC-B2 & 0.22 & 0 & 13.0 & 91.2 & 8.4 & 5.090 \\
HSC-B3 & 0.22 & 0 & 19.5 & 88.2 & 9.0 & 5.300 \\
\hline
\end{tabular}

Note: The letters in the sample number mean:

1) HSC: ultra-high-strength concrete beams;

2) A、B: the type of fiber, A that the incorporation of steel fibers, B that the incorporationof PVA fibers;

3) 1、2、3: Said fiber content (unitkg.m-3), for steel fiber on behalf of the content of 78, 156, 234, for PVA fibre on behalf of the content of $6.5,13.0,19.5$

In this paper, the steel fiber reinforced concrete beam using separate model, fiber reinforced ultra-high-strength concrete selected Solid 65 unit, for the longitudinal force steel and stirrups selected Link8 unit, A $100 \mathrm{~mm} \times 150 \mathrm{~mm}$ analog rigid plate was set at the support and loading points, The treatment method of fiber in concrete adopts modified concrete constitutive law, concrete Poisson's ratio is 0.23 。 The reinforcement of beam is modeled by bilinear isotropic hardening model (BISO), and the Poisson's ratio is 0.3 . The stress-strain relationship of the concrete before cracking and crushing is linear, and the William-Warnke failure criterion is adopted after cracking and crushing. 


\section{Finite element results and analysis}

\subsection{Analysis of flexural behavior of steel fiber reinforced ultra - high - strength concrete beams \\ 3.1.1 Cracking load and ultimate load under different steel fiber content}

Figure 2 shows the initial cracking load of ultra-high-strength concrete beams with different steel fiber content. From the data, it can be found that the initial cracking load of ultra-high-strength concrete beams is increased after the incorporation of steel fibers, and the initial cracking load increases with the increase of steel fiber content. With the increase of steel fiber content, the initial cracking load increases by $139.1 \%$ 155.4\% compared with HSC beam, which is because the incorporation of steel fiber, improve the mechanical properties of concrete, especially the splitting tensile strength.

Figure 3 shows the ultimate load of ultra-high-strength concrete beams with different steel fiber content. It can be seen from the figure, with the increase of steel fiber content, the ultimate load increases by $4.2 \%$ to 7.0\%compared with HSC beam. When the steel fiber content is $3 \%$, the ultimate bearing capacity reaches the maximum, which is $191.7 \mathrm{kN}$.

\subsubsection{Equivalent von mises stress}

Figure 4 is the equivalent cracking von Mises stress of steel fiber reinforced ultra-high-strength concrete beam, It can be seen from the figure that the maximum compressive stress in the initial cracking phase occurs in the compression zone in the middle and upper part of the beam span. The compressive stress is mainly borne by the concrete in the compression zone and the two longitudinal compressive reinforcement. The maximum compressive stress of concrete is increased with the increase of steel fiber content, and the maximum compressive stress of concrete is 2.5 times of that of HSC beam when the steel fiber content is $2 \%$. This is due to the incorporation of steel fiber, concrete and steel fiber share the stress, enhance the energy absorption of concrete, delayed the initial cracks appear, thus significantly improving the initial cracking strength.

Figure 5 is the equivalent yield von Mises stress of steel fiber reinforced ultra-high-strength concrete beam. It can be seen from the figure, the maximum compressive stress mainly occurs in the upper compression zone during the yield stage. This is mainly because the steel bar exits the work after the steel bar reaches the yield stress, and the concrete in the compression zone alone bears the stress until crushed. The maximum compressive stress of concrete increases with the increase of steel fiber content, that is, the maximum compressive stress is $2.4 \% \sim 8.8 \%$ higher
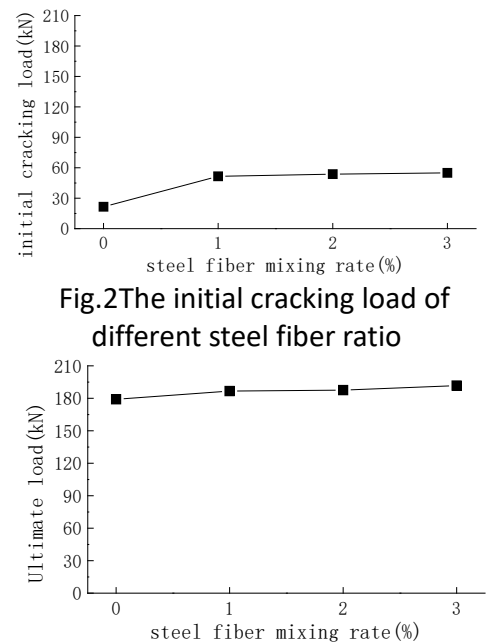

Fig.3 The ultimate load ofdifferent steel fiber ratio
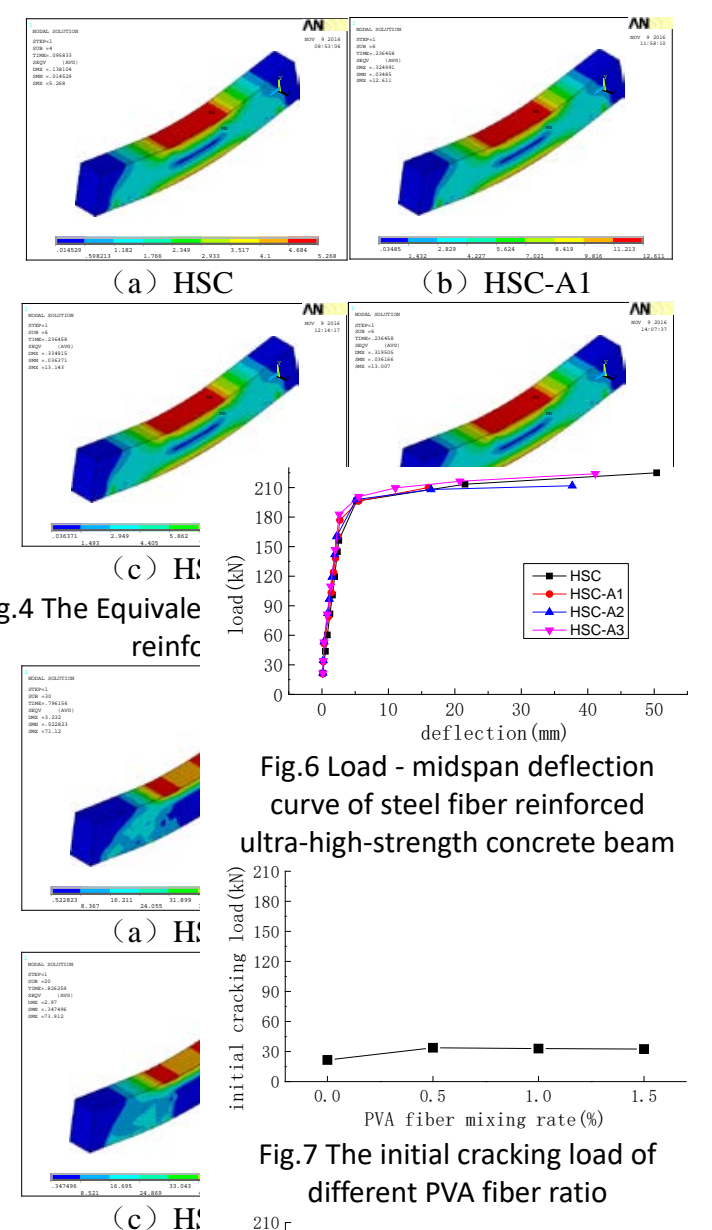

Fig. 5 The Equiva reinforced
Fig.6 Load - midspan deflection curve of steel fiber reinforced ultra-high-strength concrete beam

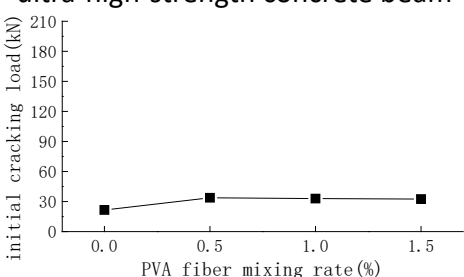

Fig.7 The initial cracking load of different PVA fiber ratio

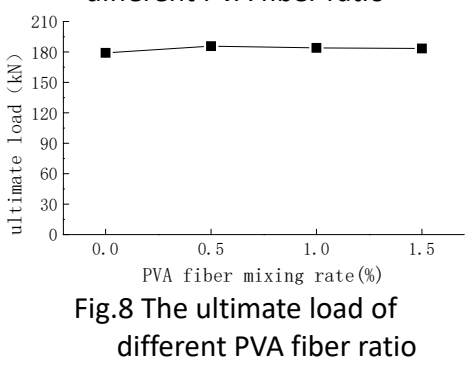


than that of HSC beam with the increase of steel fiber content.This is because with the increase of steel fiber content, the steel fiber evenly distributed in the concrete, the fibers across the cracks increased.When the internalforces redistribute, these steel fibers share the same stress, so that the matrix can continue to bear some load after cracking. It shows that the ultra-high-strength concrete beam with steel fiber has bigger load-carrying deformation capacity, the failure mode of the beam changes from brittle failure to ductile failure.

\subsubsection{Load - deflection curve}

Figure 6 is the load-midspan deflection curve of steel fiber reinforced concrete beam. It can be seen from the figure that the load-deflection changes of the concrete beams with different steel fiber ratios are similar before the yield load. The load -deflection curves of concrete beams withdifferent steel fiberratios are different after beam yield. When the beams yield, the load-deflection curves of concrete beams with different fiber content are different.That is,under the same load, the flexuralperformance of the ultra-high-strength concrete beam isimproved with the increase of the steel fiber content, the toughness is improved and the deflection is small.

\subsection{Analysis of flexural behavior of PVA fiber reinforced ultra - high - strength concrete beams}

\subsubsection{Cracking load and ultimate load under different PVA fiber content}

Figure 7 shows the initial cracking load of ultra-high-strength concrete beams with different PVA fiber content. It can be seen from the figure that the initial cracking load of thebeam first increases with the increase of the PVA fiber content, and the initial cracking load decreases slightlywhen the fiber volume fraction reaches $0.5 \%$. This is because the tensile strength of PVA fiber is much larger than that of the matrix concrete, and PVA fiber has a good rate of elongation.The incorporation of PVA fibers in the concrete inhibits the generation of cracks and limits the expansion of the base material under external force, which enhances the toughness of the beam. However, with the increase of PVA fiber content, concrete will produce more internal defects. When the reinforcing effect of the fiber on the concrete is less than the weakening effect of the defect, the flexural strength of the concrete beams decreases with the increase of the fiber content.

Figure 8 shows the ultimate load of ultra-high-strength concrete beams with different PVA fiber content. It can be seen from the figure that the effect of fiber content on the ultimate load is the same as that on initial cracking load. When the fiber content is $0.5 \%$, the ultimate load is $3.7 \%$ higher than that of HSC beam.However, with the further increase of PVA fiber content, the ultimate load slightly decreased. It is proved that the enhancement effect of PVA fiber is limited.

\subsubsection{Equivalent von mises stress}

Figure 9 shows the equivalent cracking von Mises stress of PVA fiber reinforced ultra-high-strength concrete beam.It can be seen from the figure, in the initial cracking phase of the beam, the maximum compressive stress of the concrete occurs in the upper compression zone.With the increase of PVA fiber content, the maximum compressive stress ofconcrete firstly increases and then decreases slightly, the maximum compressive stress of concrete is $56.8 \%$ higher than that of HSC beam when the mixing ratio of PVA fiber is

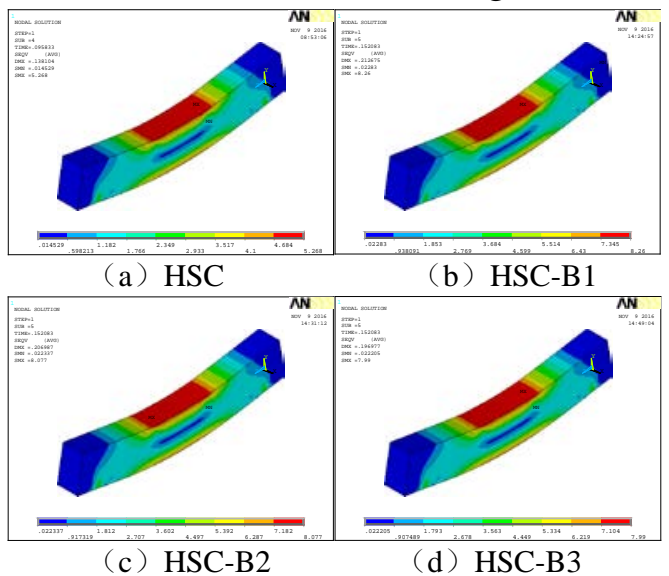

Fig.9 The Equivalent cracking von Mises stress of PVA fiber reinforcedultra-high-strength concrete beam

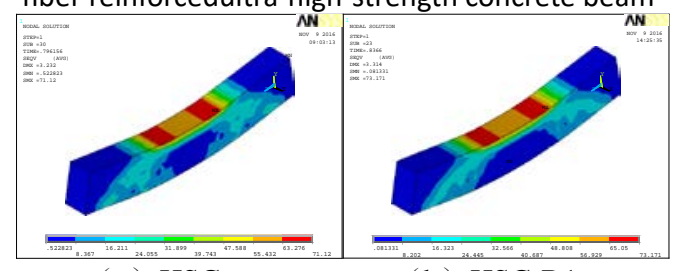

(a) HSC

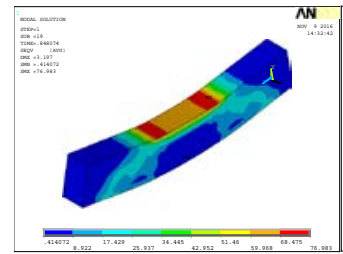

(c) HSC-B2

(b) HSC-B1

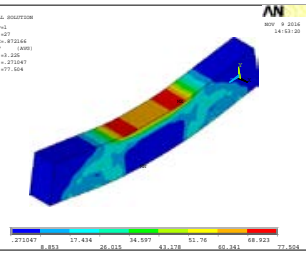

(d) HSC-B3

Fig.10 The Equivalent yield von mises stress of PVA fiber reinforcedultra-high-strength concrete beam 
$0.5 \%$,and the maximum stress is $53.3 \%$ higher than that of HSC beam when the mixing ratio of fiber is $1.0 \%$.

Figure 10 shows the equivalent yield von Mises stress of PVA fiber reinforcedultra-high-strength concrete beam.It can be seen from the figure that the maximum compressive stress in the beam during the yield stage occurs nearthe upper loading point of the beam, This is due to the fact that when the beam reaches the yield point, moreslanting cracks are created at the loading point by the support, So there is a stress concentration phenomenonnear the loading point.The maximum compressive stress of concrete increased by $2.9 \% \sim 9.0 \%$ than that of HSC beam when fiber content changed from $0.5 \%$ to $1.5 \%$. This is because when the volume fractionof PVA fibers is small, the internal force redistribution after concrete cracks is not uniform. The fiberunder high load momentarily pulls out, making the toughening effect of the fiber limited. However,with the increase of the content of PVA fiber, the fiber across the crack increases, the crack of the fiber reinforced ultra-high-strength concrete beam expands stably, so the PVA fiber plays a good toughening effect.

\subsubsection{Load - deflection curve}

Figure 11 is the load-midspan deflection curve of PVA fiber reinforced concrete beam, It can be seen from the figure, with the increase of PVA fiber mixing rate, the toughness of the ultra-high-strength concrete beam is improved. Under the sameload, the deflection of the fiber reinforced ultra-high-strength concrete beam is reduced. This is because when the concrete beam cracks, the fiber acts as a bridge force, effectively restricting the development of cracks, until the fiber is pulled out or pulled off the beam will be destroyed.

\section{4、 Simulation formula of ultimate bearing capacity of fiber reinforced ultra-high-strength concrete beams}

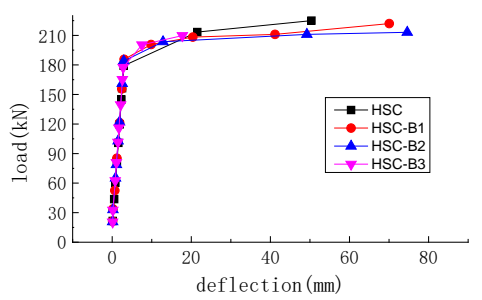

Fig.11 Load - midspan deflection curve of PVA fiber reinforced ultra-high-strength concrete beam

In order to make the fiber reinforced ultra-high-strength concrete beam better applied in practical engineering, and at the same time, it is convenient to connect with the calculation formula of normal section bearing capacity of ordinary concrete flexural members. Based on the calculation formula of bearing capacity of high - strength reinforced concrete beams, the formulas for calculating the bearing capacity of steel fiber reinforced concrete beams and PVA fiber reinforced concrete beams are deduced respectively.

According to the specification [9], the normal section bearing capacity of ordinary high-strength concrete beams is calculated according to formula (1):

$$
M_{u}=f_{y} A_{s}\left(h_{0}-\frac{f_{y} A_{s}}{2 \alpha_{1} f_{c} b}\right)(1)
$$

In the formula: $f_{y}$ is the tensile strength design value of longitudinal tensile steel bar, $A_{s}$ is thecross-sectional area of the tensile reinforcement, $f_{c}$ is the design value of axial compressivestrength of concrete, $\alpha_{1}$ is the coefficient, the concrete selects C50 to take 1 , selects C80 to take0.94, during the linear interpolation, $b$ is the width of the section, $h_{0}$ is the effective height of the beam section.

Considering the reinforcing effect of steel fiber and PVA fiber on the normal section of ultra-high-strength concrete beam.This paper assumes the following two formulas:

$$
\begin{gathered}
M_{u 1}=\left(1+k_{s} \lambda_{s}\right) M_{u}(2) \\
M_{u 2}=\left(1+k_{p} \lambda_{p}\right) M_{u}(3)
\end{gathered}
$$

In the formula, $M_{u}$ is the ultimate bearing capacity of ordinary high-strength concrete beam, its value is $179.1 \mathrm{kN} ; M_{u_{1}}$ is the maximum bending moment of steel fiber reinforced ultra-high-strength 
concrete beam; $k_{s}$ is the enhancement coefficient of the steel fiber; $k_{p}$ is the enhancement coefficient of the PVA fiber; $\lambda_{s}$ is the characteristic value of steel fiber content; $\lambda_{p}$ is thecharacteristic value of PVA fiber content; The coefficients $k_{s}$ and $k_{p}$ are derived bycalculation. The bending moment of the beam cross section is calculated as $M=P \times L$, All the testbeams in this paper have the same size and loading position, that is, $L=0.4 \mathrm{~m}$, Therefore, the ultimate load $P$ can be used instead of $M$ to derive $k_{s}$ and $k_{p}$.

Firstly, the steel fiber reinforced coefficient $k_{s}$ is deduced.

Taking the ultra - high - strength concrete beam with 1\% steel fiber volume fraction (HSC-A1) as an example, According to the physical properties of steel fiber, steel fiber length $l_{f}=30 \mathrm{~mm}$, diameter $d_{f}=0.55 \mathrm{~mm}, \lambda_{s}$ is defined as $\rho_{s} l_{f} / d_{f}=1.0 \% \times 54.5=0.55$, Bringing $M_{u}=179.1 \mathrm{kN}$ and $M_{u 1}=186.7 k N$ into formula (2), obtained $k_{s}=0.077$; Similarly, The beam HSC-A2 can be obtained $k_{s}=0.043$; The beam HSC-A3 can be obtained $k_{s}=0.043$; Take the average of threebeams, get $k_{s}=0.054$, So the ultimate bearing capacity of the steel fiber reinforcedultra-high-strength concrete beam can be calculated as:

$$
M_{u 1}=\left(1+0.054 \lambda_{s}\right) M_{u}(4)
$$

Secondly, the PVA fiber reinforced coefficient $k_{p}$ is deduced.

Taking the ultra-high-strength concrete beam with 0.5\% PVA fiber volume fraction (HSC-B1) as an example, According to the physical properties of PVA fiber, PVA fiber length $l_{f}=12 \mathrm{~mm}$, diameter $d_{f}=0.1 \mathrm{~mm}, \lambda_{p}$ is defined as $\rho_{p} l_{f} / d_{f}=0.5 \% \times 120=0.6$, Bringing $M_{u}=179.1 \mathrm{kN}$ and $M_{u 1}=185.7 k N$ into formula (3) , obtained $k_{p}=0.061$; Similarly, The beam HSC-B2 can be obtained $k_{p}=0.023$; The beam HSC-B3 can be obtained $k_{p}=0.013$; Take the average of threebeams, get $k_{p}=0.032$, So the ultimate bearing capacity of the PVA fiber reinforcedultra-high-strength concrete beam can be calculated as:

$$
M_{u 2}=\left(1+0.032 \lambda_{p}\right) M_{u}(5)
$$

\subsection{Comparison of calculated values and simulated values}

Fig.12 and Fig.13 are the scatter diagram of the calculated values and simulated values of the flexural capacity of the steel fiber reinforced concrete beams and the PVA fiber reinforced concrete beams, respectively. From the figure, it can be seen that the difference between the calculated value and the simulated value is within the range of $5 \%$, so the formula deduced in this paper can meet the practical application requirements.

\section{5.conclusion}

In this paper, the influence of steel fiber and PVA fiber on the initial cracking load and ultimate load of ultra-high-strength concrete beam under different mixing rates are studied by ANSYS finite element simulation. The results show that:

(1) With the increase of steel fiber content, the initial cracking load and ultimate load of the ultra-high-strength concrete beam are increased. When the steel fiber content is 3\%, the initial cracking load and ultimate load of the beam reach the maximumvalue, With the increase of the steel fiber content, the deflection of the beam under the same load gradually decreases.

(2) With the increase of PVA fiber content, the initial

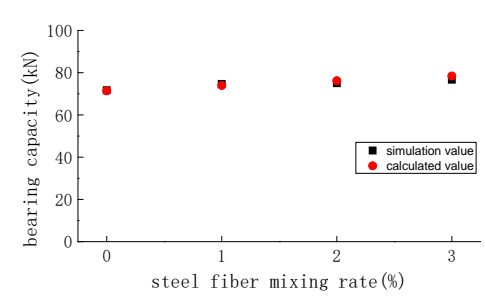

Fig.12 the calculated value and the simulation valueof steel fiberreinforced ultra-high-strength concrete beam

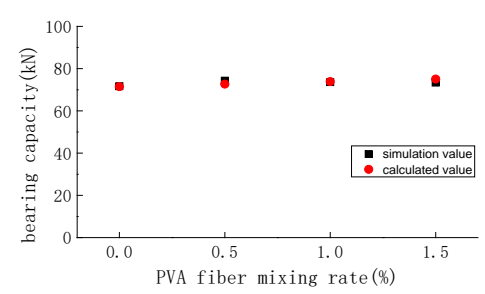

Fig.13 the calculated value and the simulation valueof PVAfiber reinforced ultra-high-strength concrete beam 
cracking load and ultimate load of the ultra-high-strength concrete beam increase first and then decrease, but they are higher than HSC beam. When the fiber content is $0.5 \%$, the initial cracking load and the ultimate load of the beam reach the maximum.

(3) Based on the calculation formula of flexural capacity of ordinary reinforced concrete beams, the formula for calculating the flexural capacity of steel fiber reinforced ultra-high-strength concrete beams and PVA fiber reinforced ultra-high-strength concrete beams is presented in this paper.

\section{References}

[1]Chenghui Sun. Study on brittleness improvement of super high strength concrete [D].North China University of Technology, 2013.

[2]Xincheng $\mathrm{Pu}$, Zhijun Wang, Wang Chong, Wunan Yan, Yongwei Wang. Study on mechanical properties of ultra high strength and high performance concrete[J]. Journal of Building Structures, 2002, 06:49-55.

[3]Yudong Tian, Xiuli Du,Li Rui. Study on preparation and basic mechanical properties of super high strength concrete[J]. Concrete, 2008, 04:77-80.

[4]Ouyang Dong, Yu Bin. Study on the basic mechanical properties of super high strength concrete[J]. Journal of Chongqing Jianzhu University， 2003， 04:38-42.

[5]Xiuli Du, Yudong Tian, Guoqin Dou. Experimental study on preparation and mechanical properties of fiber super-high-strength concrete[J]. Concrete and cement products, 2011, 02:44-48+71.

[6]Changwang Yan, Zhang Ju, Jinqing Jia. Experimental study on tension-pressure ratio of high elastic modulus PVA fiber ultra-high-strength concrete [J]. Journal of Inner Mongolia University of Technology (Natural Science Edition), 2012, 01:58-62.

[7]Changwang Yan, Jinqing Jia, Zhang Ju. Experimental study on tensile compression ratio of steel fiber reinforced ultra high strength concrete[J]. Journal of Dalian University of Technology, 2012, 02:233-238.

[8]Jianzhong Liu, Fangyu Han, Gong Cui, Qianqian Zhang,Jin Lv,Lihui Zhang,Zhiqian Yang,Combined effect of coarse aggregate and fiber on tensile behavior of ultra-high performance concrete, Constr. Build. Mater. 121 (2016) 310-318.

[9] China Academy of Building Research.GB50010 - 2002Code for design of concrete structures[S].Beijing: China Architecture and Building Press, 2002. 